\title{
Gender differences in mathematics anxiety and the relation to mathematics performance while controlling for test anxiety
}

Amy Devine ${ }^{1}$, Kayleigh Fawcett ${ }^{1}$, Dénes Szücs ${ }^{1 *}$ and Ann Dowker ${ }^{2}$

\begin{abstract}
Background: Mathematics anxiety (MA), a state of discomfort associated with performing mathematical tasks, is thought to affect a notable proportion of the school age population. Some research has indicated that MA negatively affects mathematics performance and that girls may report higher levels of MA than boys. On the other hand some research has indicated that boys' mathematics performance is more negatively affected by MA than girls' performance is. The aim of the current study was to measure girls' and boys' mathematics performance as well as their levels of MA while controlling for test anxiety (TA) a construct related to MA but which is typically not controlled for in MA studies.
\end{abstract}

Methods: Four-hundred and thirty three British secondary school children in school years 7, 8 and 10 completed customised mental mathematics tests and MA and TA questionnaires.

Results: No gender differences emerged for mathematics performance but levels of MA and TA were higher for girls than for boys. Girls and boys showed a positive correlation between MA and TA and a negative correlation between MA and mathematics performance. TA was also negatively correlated with mathematics performance, but this relationship was stronger for girls than for boys. When controlling for TA, the negative correlation between MA and performance remained for girls only. Regression analyses revealed that MA was a significant predictor of performance for girls but not for boys.

Conclusions: Our study has revealed that secondary school children experience MA. Importantly, we controlled for TA which is typically not controlled for in MA studies. Girls showed higher levels of MA than boys and high levels of MA were related to poorer levels of mathematics performance. As well as potentially having a detrimental effect on 'online' mathematics performance, past research has shown that high levels of MA can have negative consequences for later mathematics education. Therefore MA warrants attention in the mathematics classroom, particularly because there is evidence that MA develops during the primary school years. Furthermore, our study showed no gender difference in mathematics performance, despite girls reporting higher levels of MA. These results might suggest that girls may have had the potential to perform better than boys in mathematics however their performance may have been attenuated by their higher levels of MA. Longitudinal research is needed to investigate the development of MA and its effect on mathematics performance.

\footnotetext{
* Correspondence: ds377@cam.ac.uk

${ }^{1}$ Department of Experimental Psychology, University of Cambridge, Downing

Street, Cambridge CB2 3EB, UK

Full list of author information is available at the end of the article
}

\section{Biomed Central}

(c) 2012 Devine et al.; licensee BioMed Central Ltd. This is an Open Access article distributed under the terms of the Creative Commons Attribution License (http://creativecommons.org/licenses/by/2.0), which permits unrestricted use, distribution, and reproduction in any medium, provided the original work is properly cited. 


\section{Background}

Mathematics anxiety (MA) is generally defined as a state of discomfort caused by performing mathematical tasks [1]. MA can be manifested as feelings of apprehension, dislike, tension, worry, frustration, and fear [2-4]. It is not clear what factors result in the appearance of MA. Nevertheless, potential causal factors include environmental variables (e.g., negative experiences in class, teacher characteristics), intellectual variables (e.g., the degree of abstract or logical thinking) and personality variables (e.g., self-esteem, learning style, attitude and confidence $[5,6])$.

MA can develop in the early school years [5,7] and becomes increasingly common with age $[8,9]$. It is thought to affect a notable proportion of the school age population $[2,10,11]$ and adults in post-secondary education [12]. Importantly, MA has several negative effects on children's and adult's mathematics education. For example, people who experience high levels of MA are likely to develop negative attitudes toward tasks involving mathematics, drop out of elective mathematics classes or avoid taking them altogether; in addition, those with high MA avoid pursuing careers that require quantitative skills [3,13-15]. This can have large-scale implications. For example, only $7 \%$ of pupils in the UK take mathematics to A level, and while there are many reasons for this, many pupils give a dislike of mathematics as a reason for not continuing [16] and sometimes the dislike is very intense and 'charged with emotion' [ibid, p. 10].

Some have viewed MA as form of Test Anxiety (TA) [17]. Studies have shown moderate correlations between TA and MA (between .30 and .50), so they are indeed related constructs; however, measures of MA correlate more highly with one another (between .50 to .80 ) than with TA, which suggests that MA is a distinct construct $[2,18,19]$.

Of all of the negative effects that MA has on learning and using mathematics, the relationship between MA and mathematics performance has received the most attention. Past research has shown small negative correlations between mathematics performance and MA (average correlations of -.27. and -.34 in two metaanalyses) [11,19-24], indicating that those with high MA show poorer mathematics achievement. However, it has been argued that mathematics achievement, when measured in test situations, is always confounded with MA $[2,25]$. That is, the mathematics performance of highly mathematics anxious individuals is impaired because of their "online emotional reaction to the testing situation" [2, p. 320]. Consequently, the mathematics performance of an individual with high MA may appear lower than it actually is, when measured using a test. Furthermore, time-limited testing can negatively affect the performance of high and low maths anxious individuals, but performance is not differentially affected in the two groups [26]. However, individuals with high MA can perform similarly to individuals with low MA when mathematics problems are presented in a more relaxed format [13]. Therefore, the depressed performance associated with high MA and the reported negative correlations between MA and performance may be exaggerated because of the context in which mathematics performance is measured. Nonetheless, the effect of MA on 'online' mathematics performance is still pertinent, as mathematics achievement, particularly in secondary and tertiary education, is measured using time-limited tests and formal examinations. Therefore, the assessment of MA in realistic test situations is highly important as these situations exert marked influence on individual career prospects and well-being.

Further research has explored the direction of the relationship between MA and performance and two major theories have been proposed. The Deficit Theory [27], claims that anxiety emerges a result of an awareness of poor mathematics performance in the past. In contrast, the Cognitive Interference Theory [28] posits that high levels of anxiety interfere with the recall of prior learning resulting in poorer performance. A meta-analysis conducted by Hembree [19] of 151 studies of MA found more evidence to support the Cognitive Interference Theory than the Deficit Theory. However, in a more recent investigation, Birgin and colleagues found that the highest unique contribution to children's MA was from the children's mathematics performance [29]. Similarly, in one of the few longitudinal investigations, $\mathrm{Ma}$ and $\mathrm{Xu}$ [3] found that poorer mathematics performance led to higher MA in junior and senior high school students. Together these studies lend support to the Deficit Theory. MA resulting from an awareness of prior poor performance may be related to mathematics self-efficacy beliefs as past studies have shown that maths self-efficacy is highly predictive of MA [30-32]. The findings of two recent studies that children with diagnosed mathematical disabilities show more MA $[33,34]$ could also indicate that poor performance leads to greater MA, though we cannot rule out the possibility that the disabilities were indeed partly caused by anxiety. Evidently the directionality of the relationship between MA and performance is open for debate and requires further research.

The relationship between gender and MA has also been studied extensively; but findings have not been consistent. There are many studies that have found significantly greater levels of MA in females than males $[4,6,12,13,15,19,32,35-51]$. However, there are also many studies that show no gender differences in MA 
$[3,5,7,10,29,52-61]$. There are indeed a few studies that have found higher MA levels in males than in females [62-64].

Birgin and colleagues have suggested that the lack of consistent gender effects may be because MA is not consistently defined or measured [29]. Indeed, many different MA measures have been used in past studies. The most frequently used scale is the Mathematics Anxiety Rating Scale (MARS) which has 98 items [65]. The large number of items in the scale allows the assessment of mathematics anxiety in a wide range of contexts and is therefore thought to have high construct validity. However, it requires a considerable amount of time for administration, which may make it more difficult to use with school age samples. Therefore several different shortened versions of the MARS have been developed [64,66-69], however the psychometric properties of these shortened scales have come under scrutiny [22]. Hopko and colleagues developed a 9-item scale known as the Abbreviated Math Anxiety Scale (AMAS) which was found to have strong test-retest reliability, good internal consistency and validity $[22,41]$.

In comparison to the number of studies that have investigated gender differences in overall levels of MA, relatively few studies have explored whether the relationship between MA and maths performance or maths achievement differs by gender. Betz [12] found that correlations between MA and mathematics performance for University students differed according to gender and course: female psychology students showed a significant correlation between MA and mathematics achievement test scores, whereas males did not; in contrast, correlations between MA and mathematics achievement test scores emerged for both genders in students enrolled in an advanced mathematics course. Hembree's metaanalysis revealed that females' higher MA did not result in poorer mathematics performance and that MA was more predictive of maths performance in males [19]. Similarly, Miller and Bichsel [24] found that MA was more predictive of basic maths performance in males than in females; but MA was not more predictive of applied mathematics performance in either gender. Ma and $\mathrm{Xu}$ [3] also found gender differences in the relationship between MA and achievement. Specifically, they found that boys' prior low maths achievement predicted later high MA at all grade levels, however girls' prior low maths achievement only predicted later high MA at critical transition points during schooling (for example, transferring from middle school to secondary school). A possible explanation for the findings of a greater relationship between MA and achievement in males is that girls tend to experience MA whether or not they have any intrinsic difficulties in mathematics, whereas MA in boys is more likely to reflect initial problems in the subject. Alternatively, boys' performance may be more negatively affected by anxiety, perhaps because it is less socially acceptable for them to communicate their anxieties, and thus they may be less likely to develop or be shown effective strategies of dealing with anxiety.

On the other hand, other studies have failed to find gender differences in the relationship between MA and performance/achievement [32,59]; Ma [23] gives a metaanalysis of such studies.

The general pattern of results suggests that there is a relationship between $\mathrm{MA}$ and maths performance or achievement, but that the direction of the relationship is not clear, partly due to the fact that studies have generally been correlational rather than longitudinal. Also, different studies have used different measures of both mathematical performance and of MA, making their results hard to compare given that some measures used may have been less reliable than others.

Given the mixed results in the field it is clear that further research, utilising reliable measures of MA, is necessary to investigate gender differences in MA and the relationship between MA and performance. The current study aims to identify whether a gender difference exists in overall levels of MA in 11- to 16-year-old children, and whether the relationship between MA and mathematics performance differs for boys and girls. The current study uses a brief MA scale, the AMAS, which is appropriate for use with young children. Furthermore the current study controls for test-anxiety which is typically not controlled for in MA studies.

It was predicted that girls would report higher MA than boys. It was also predicted that there would be a negative correlation between MA and maths performance for boys and girls, and that this correlation will be stronger for boys than girls.

\section{Method \\ Participants}

482 secondary school pupils were studied in total. 49 pupils were excluded from the investigation because they did not give at least one correct response in the mathematics test (41 pupils: 28 boys and 13 girls) or because they did not fill in the MA questionnaire (8 pupils). We decided to exclude the 41 pupils who did not fill out the mathematics test because it was hard to decide whether they did so because they were genuinely unable to solve a single task (which is very unlikely) or because they were not motivated to respond to the questions. The remaining 433 children (165 girls and 268 boys) were included in the sample: 158 children in Year 7 (mean age $=12.13$ years, $S D=0.43$ years), 137 in Year 8 (mean age $=13.01$ years, $\mathrm{SD}=0.44$ years $)$ and 138 in Year 10 (mean age $=15.14$ years; $S D=0.40$ years). Participants attended a rural comprehensive secondary school 
located in England, UK. The catchment area of the school was predominantly working class and lowermiddle class. Participants and guardians gave appropriate informed written consent. The study was approved by the Departmental Research Ethics Committee of the Faculty of Education, University of Cambridge. The research was in compliance with the Helsinki Declaration.

\section{Measures and procedure}

\section{Mathematics anxiety}

The Abbreviated Math Anxiety Scale (AMAS) [22] was used to measure levels of maths anxiety. This is the shortest valid maths anxiety scale - with only 9 items, using a 5-point scale and, as mentioned earlier, has been shown to be just as effective as the longer MARS [22,41] (internal consistency: $\alpha=.90$; two-week test-retest reliability: $r=.85$; convergent validity of AMAS and MARS$\mathrm{R} r=.85)$.

\section{Test anxiety}

Sarason's Test Anxiety Scale [70] was used to measure test anxiety. The questionnaire contains 36 items which deal with physiological, emotional, cognitive and behavioural reactions during test-taking situations. Participants indicate whether they believe the item applies to them by answering 'True' or 'False'. This questionnaire was developed many years ago. Hence, we assessed its reliability by computing Cronbach's alpha and odd-even split-half reliability in our own sample. Cronbach's alpha was 0.86 , split-half reliability was 0.88 . These values can be considered good. Hence, the TA questionnaire was reliable.

\section{Mathematics performance}

Custom made mental mathematics tests were used in order to assess mathematical performance. Each year group was given a specific mathematics test suitable for their age range fitted to the content of their school material. The Year 7 and 8 tests each contained 20 problems and the Year 10 test contained 25 problems. The problems were written in Arabic digits rather than in words in order to minimise effects of reading problems and comprised of addition, subtraction, multiplication and division questions. We purposefully excluded rotelearned multiplication problems (i.e., common 'times tables') in the tests so that participants would utilize their working memory for calculation rather than simply retrieving the answers from long term memory [71]. Participants were allowed 5 minutes to complete the mental mathematics test, and were informed of this at the beginning of the session. As previous studies suggest this time pressure is not expected to have a differential effect on the performance of individuals with low and high maths anxiety [26].
All participants were tested in groups of 80 to 200, under examination conditions in their school exam hall. Each session was led by a researcher and invigilated by the participants' teachers. Mathematics tests were administered prior to the MA and TA questionnaires.

\section{Statistics}

Our main interest was to examine the interrelationship of MA, TA and maths performance as well as their relation to gender. Hence, in order to assure comparability across year groups, the data was standardized separately for each year group, using the mean and standard deviation of each year group. First, a Multivariate Analysis of Variance (MANOVA) was run on MA, TA and performance scores as dependent variables with factors gender (male vs. female) and school year (Year 7 vs. Year 8 vs. Year 10). Then univariate Analyses of Variance (ANOVAs) were run on each dependent variable with factors and gender and year. Other ANOVAs were run separately for girls and boys with a year factor. Pearson correlations were computed with MA, TA and performance. Partial correlations were used to control for the effect of TA. Simultaneous multiple linear regression was used to assess the relationship of mathematics performance, MA and TA. MA and TA were used as predictors of mathematics performance.

\section{Results}

Additional file 1: Figure S1 demonstrates the MA scores of excluded participants: scores cover the whole available spectrum. In this sample the mean \pm standard deviation of MA was $0.62 \pm 1.35$ (minimum; -1.98; maximum: 3.56) which fits the group average. The following describes the results from the main sample.

Gender differences on the three measures are depicted in Figure 1. The MANOVA found the gender factor

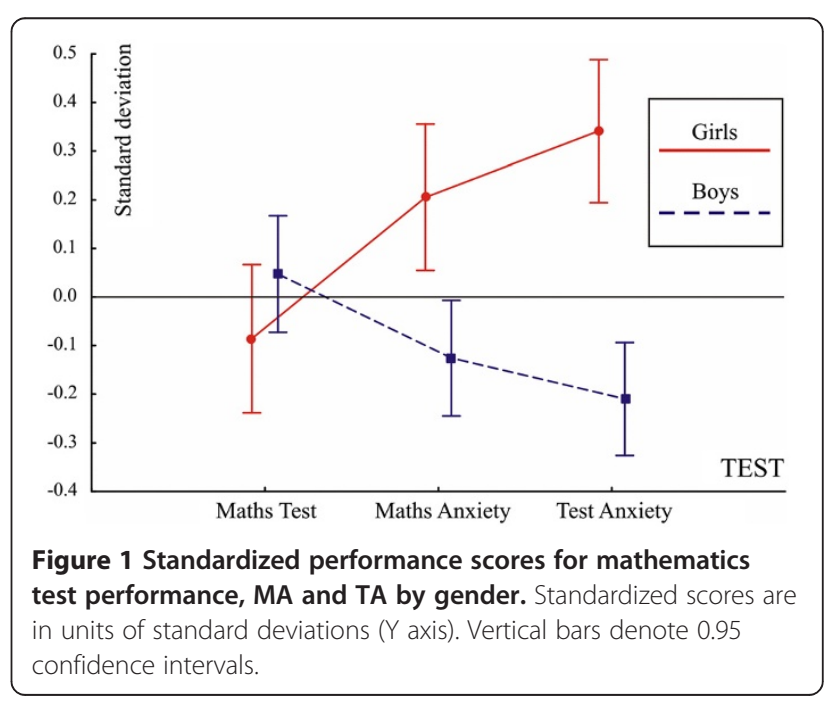


highly significant (Wilks: $F(3,427)=11.57$; $\mathrm{p}<0.0001$ ). According to univariate ANOVAs mathematics test performance was not different between girls and boys $(-0.08$ vs. 0.04 standard deviations; $p=0.2)$. In contrast, MA was 0.33 standard deviations higher in girls than in boys $(0.2$ vs. -0.13 standard deviations; $F(2,429)=11.52$; $\mathrm{p}=0.0007)$. In addition, TA was also 0.55 standard deviations higher in girls than in boys $(0.34$ vs. -0.21 standard deviations; $\mathrm{F}(2,429)=33.51 ; \mathrm{p}<0.0001)$. There were no other significant effects.

A single boy showed by the boxes in Figure 2B and Figure $3 \mathrm{~B}$ showed highly outlying scores (maths performance $=2.41 ; \mathrm{MA}=3.19$; $\mathrm{TA}=-0.85$ ). Hence, this individual was excluded from correlation and regression analyses. (Nevertheless, all analyses were also run including this individual and the pattern of results did not change.) Correlation analyses established that in girls, MA was positively correlated with TA (Pearson $\mathrm{r}=0.363 ; \mathrm{p}<0.001$. Spearman $\mathrm{R}=0.362 ; \mathrm{p}<0.001$ ) and negatively correlated with mathematics performance (Pearson $\mathrm{r}=-0.349 ; \mathrm{p} \quad<0.001$. Spearman $R=-0.325 ; \quad p \quad<0.001 ; \quad$ See this relationship in Figure 2A.). TA was also negatively correlated with maths performance (Pearson $\mathrm{r}=-.207 ; \mathrm{p}=0.008$. Spear$\operatorname{man} \mathrm{R}=-0.195 ; \mathrm{p}<0.05)$.

In boys MA was positively correlated with TA (Pearson $\mathrm{r}=.759 ; \mathrm{p}<0.001$; Spearman $\mathrm{R}=0.491 ; \mathrm{p}<0.001)$ and negatively correlated with performance (Pearson $\mathrm{r}=-0.180 ; \mathrm{p}=0.003 ;$ Spearman $\mathrm{R}=-0.172 ; \mathrm{p}<0.001$; See Figure 2B.). In contrast to girls, the correlation of TA and performance was only marginally significant in boys (Pearson $r=-0.110 ; p=0.07$; Spearman $R=-0.106$; $\mathrm{p}<0.07)$. According to a difference test the strength of the correlation between MA and performance was significantly different in girls and boys (for Pearson $r$ values: $p=0.0333$ ).
The relationship of MA and TA in girls and boys is shown in Figure 3. The effect of TA was controlled for in partial correlation analyses. In girls MA remained strongly negatively correlated with performance $(\mathrm{r}=-.301 ; \mathrm{p}<0.001)$. In contrast, the correlation of MA and performance was only marginally significant in boys $(r=-0.108 ; p=0.07)$. According to a difference test the strength of the MA vs. performance correlation was significantly different in girls and boys $(\mathrm{p}=0.0233)$. In opposing analyses MA was controlled for. In these analyses mathematics test performance was not correlated with TA in either girls $(\mathrm{p}=0.25)$ or boys $(\mathrm{p}=0.37)$.

In girls the regression model (based on standardized scores) was highly significant $(\mathrm{F}(2,162)=12.06$; $\mathrm{p}<0.0001)$. The model accounted for $11.88 \%$ of the variance $\left(R^{2}\right)$. MA was a significant predictor variable of performance (Beta $=-.315 ; \mathrm{p}<0.0001$ ). In contrast, test anxiety was not a significant predictor. In boys the overall model reached significance $(F(2,264)=3.03 ; \mathrm{p}<0.05)$. However, it accounted only for $1.5 \%$ of the variance and neither MA, nor test anxiety emerged as significant predictors of performance.

\section{Discussion}

We found significant negative correlations between MA and mathematics performance for boys and girls, indicating that children with higher mathematics anxiety have lower mathematics performance. These correlations support the findings of two meta-analyses which found moderate negative correlations between MA and performance (correlations of -.34 and -.27) [19,23]. In contrast, we found no difference between girls' and boys' mathematics performance. The lack of gender difference in mathematics performance is in line with research showing that gender differences in mathematics
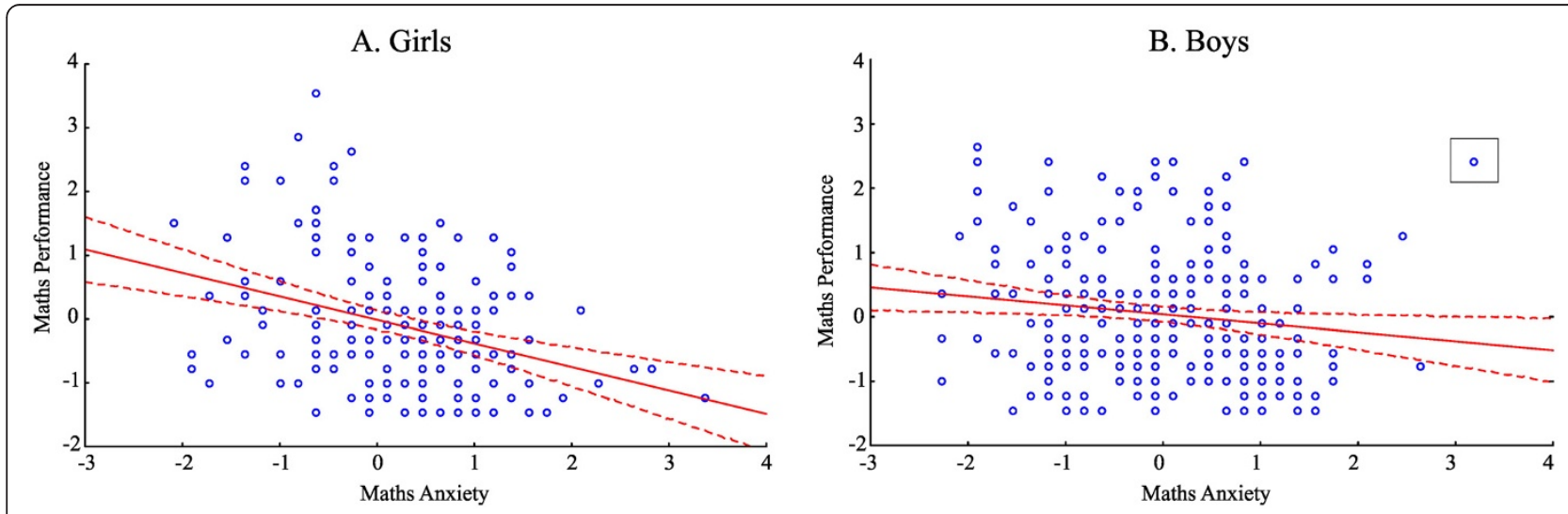

Figure 2 The correlation between mathematics performance and MA for girls (2A) and boys (2B). Mathematics performance and MA are given in standardized scores in units of standard deviations ( $Y$ axis). The box in the upper right corner marks an outlier; see text for further explanation. 


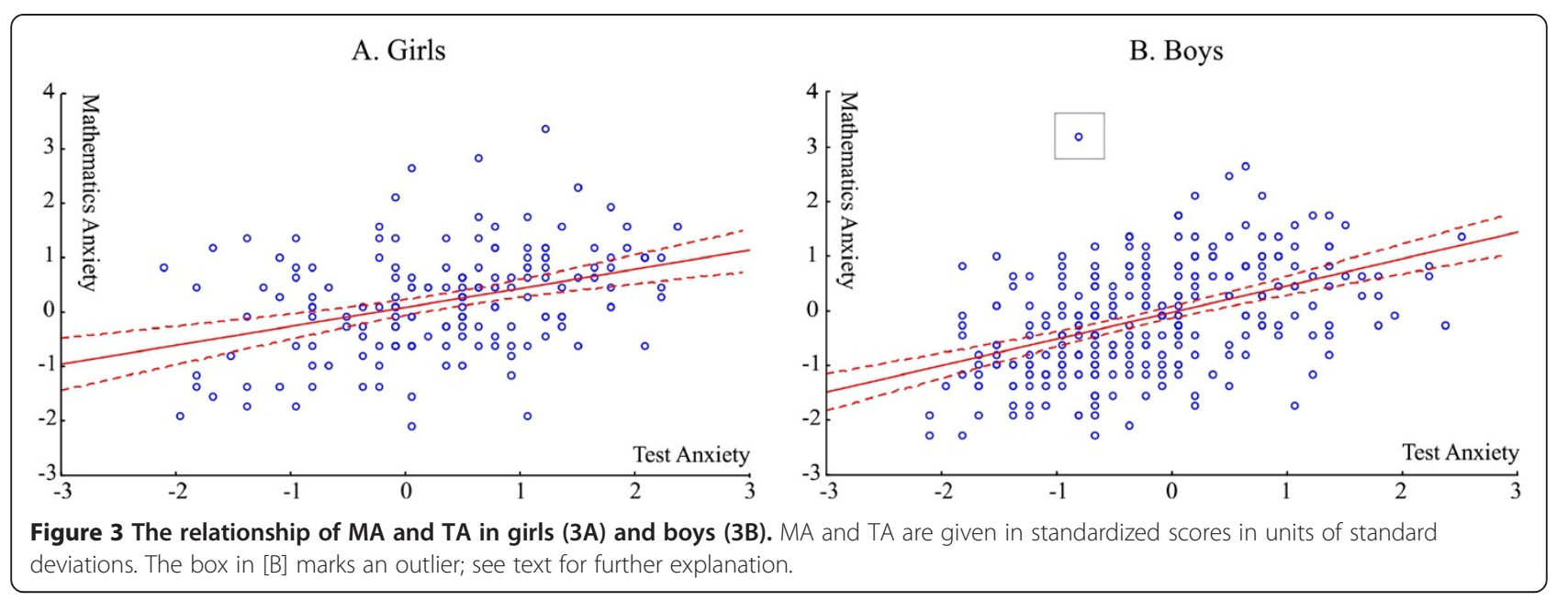

performance are declining, or non-existent in genderequal countries [40,72-74].

Overall, girls reported higher levels of MA than boys, supporting our hypothesis. This finding is in line with the many other studies cited in the Introduction that found higher levels of MA in females than males, though as noted there such findings are not universal.

The reasons for why females frequently report higher MA than males is not well understood but several explanations have been offered. Some have suggested that the different ways in which boys and girls are socialized during childhood may differentially affect the anxiety experienced by males and females in certain situations [75]. This hypothesis, known as the sex-role socialization hypothesis, argues that because mathematics is traditionally viewed as a male domain, females may be socialized to think of themselves as mathematically incompetent and therefore females may avoid mathematics and when females do participate in mathematical activities they may experience more anxiety than males $[75,76]$. However, no link between MA and sex-role has been found and the view that mathematics is a male domain is decreasing $[30,46,75,77,78]$. Therefore, this hypothesis is unlikely to explain effects fully.

Another possible explanation for the gender difference in MA is that females may be more willing to admit to feelings of anxiety than males because the expression of emotion by females may be accepted whereas the expression of anxiety in males may be viewed as less acceptable [77,78]. Research has shown that females/ feminine individuals are more likely to express feelings of anxiety or psychological distress than males/masculine individuals [79-81]. Flessati and Jamieson [78] tested whether gender-linked response biases can account for females showing higher MA than males by asking their participants which gender was more likely to be anxious about mathematics and other school subjects; and whether participants viewed MA as being acceptable in males, females and themselves. Contrary to the response bias hypothesis, Flessati and Jamieson found that their participants believed that MA affected both genders equally and that MA was more acceptable in males than females. Interestingly, Flessati and Jamieson found that females were more critical of the expression of MA in themselves. This finding led Flessati and Jamieson to argue that the gender difference in MA could be explained by females being more self-critical, however no follow-up research was conducted to investigate this claim.

Other variables that may account for the gender difference in MA are mathematics confidence/self-concept and mathematics self-efficacy. Several studies have shown that boys report greater confidence in mathematics than girls [76,82-86]. As mentioned previously, a similar concept, mathematics self-efficacy, has been shown to be related to MA [30,32] and boys also report higher maths self-efficacy than girls [87].

An alternative view, the maths experiences hypothesis [17] claims that gender differences in MA disappear when mathematical background is taken into account (the amount of interaction with mathematics and the number of positive/negative experiences), a finding that has been shown in college student samples [88]. However, other studies have shown that, even though maths experience is related to level of MA, maths experience does not account for the gender difference in MA $[77,78]$.

Our study also revealed that girls showed higher TA than boys. Many of the proposed explanations for the gender difference in MA could account for the gender difference in TA too, for example, gender-linked response biases, or gender differences in self-confidence or self-efficacy. What is more interesting however is that girls showed a strong negative relationship between MA 
and mathematics performance, which remained even when TA was controlled for. On the contrary, boys only experienced marginal effects of general TA on performance, and when TA was controlled for, they only showed a marginal relationship between MA and performance. These results suggest that anxiety experienced by boys may simply reflect general test anxiety, whereas girls experience specific anxiety towards mathematics, which is above and beyond any general anxiety associated with testing situations. The regression model suggests MA predicts mathematics performance for girls but not for boys. Overall, these results might suggest that MA affects girls' mathematics performance more than boys' mathematics performance, although, we did not measure the direction of this relationship so we cannot determine whether MA affects performance or whether maths performance influenced the participants' anxiety levels.

The finding that MA predicted performance more in girls than boys contradicts some previous findings which suggested either a greater MA-performance relationship in males, or no gender differences in this relationship. This could reflect some differences between this sample and the other (mostly American) samples that have been studied; or it could reflect the fact that other studies typically have not investigated or controlled for the effects of general TA.

However we should not forget that despite the stronger relationship between MA and performance which emerged for girls, girls' maths performance was not significantly different to boys' maths performance. Given that girls reported higher levels of MA than boys it is possible that girls' mathematics performance was actually confounded by MA, or the time-limited testing procedure, and the mean score reported in the current study may not reflect the girls' true mathematical ability: i.e., they might actually have had the potential to perform better than the boys. This is a general problem with studies of MA in relation to performance, as it is difficult to measure mathematics performance without administering a test and/or making use of existing school test scores.

Further research should involve investigating mathematics anxiety and mathematical performance longitudinally from early primary school years onwards. Some research suggests that younger children show both lower levels of MA and less of a relationship between anxiety and performance than do older children and adults $[9,89]$. This could be due to several possible reasons. It may be that experiences of failure or negative evaluations in mathematics lead to an increase in MA, possibly resulting in a vicious circle, which also leads to an everincreasing $\mathrm{MA} /$ performance relationship. It may also be that MA increases with age for other reasons, and that it only has a negative impact on performance when it reaches a certain level of severity; indeed some have suggested an inverted U-shaped relationship between MA and performance, with moderate MA leading to better performance than no MA at all [90]. Longitudinal studies starting at an early age could give a better indication of the direction of causation, and whether it differs between the genders. It would also be desirable to use not only explicit measures of MA, but implicit measures such as arithmetic-affective priming [34] and/or measures of physiological indicators of anxiety. This could reduce the possible influence of gender differences in the willingness to report anxiety.

\section{Conclusions}

Our study has revealed that secondary school children experience MA. Importantly, girls showed higher levels of MA than boys and high levels of MA were related to poorer levels of mathematics performance. As well as potentially having a detrimental effect on 'online' mathematics performance, past research has shown that high levels of MA can have negative consequences for later mathematics education. Therefore MA warrants attention in the mathematics classroom, particularly because there is evidence that MA develops during the primary school years. Furthermore, our study showed no gender difference in mathematics performance, despite girls reporting higher levels of MA. These results might suggest that girls may have had the potential to perform better than boys in mathematics however their performance may have been attenuated by their higher levels of MA. Longitudinal research is needed to investigate the development of MA and its effect on mathematics performance.

\section{Additional file}

Additional file 1: Figure S1. Standardized MA scores of excluded participants. Scores are in units of standard deviations ( $Y$ axis).

\section{Abbreviations}

MA: Maths anxiety; TA: Test anxiety.

\section{Competing interests}

The authors declare that they have no competing interests

\section{Acknowledgements}

We thank Prof. Usha Goswami for comments on an earlier draft of this manuscript. This study was supported by grant G90951 (DS) from the Medical Research Council.

\section{Author details}

${ }^{1}$ Department of Experimental Psychology, University of Cambridge, Downing Street, Cambridge CB2 3EB, UK. ${ }^{2}$ Department of Experimental Psychology, South Parks Road, Oxford OX1 3UD, UK.

\section{Authors' contributions}

KF and DS designed the study. KF collected the data. DS analyzed the data, contributed to the interpretation of the data and to the preparation of the manuscript. $A D(1)$ contributed to the interpretation of the data and drafted 
the manuscript. $A D(2)$ contributed to the interpretation of the data and contributed to the preparation of the manuscript. All authors read and approved the final manuscript.

Received: 21 November 2011 Accepted: 9 July 2012

Published: 9 July 2012

\section{References}

1. Ma X, Xu J: The causal ordering of mathematics anxiety and mathematics achievement: a longitudinal panel analysis. J Adolesc 2004, 27:165-179.

2. Ashcraft MH, Ridley KS: Math anxiety and its cognitive consequences: a tutorial review. In The Handbook of Mathematical Cognition. Edited by Campbell JID. New York: Psychology Press; 2005:315-327.

3. $\mathrm{Ma} X, \mathrm{Xu}$ J: Determining the causal ordering between attitude toward mathematics and achievement in mathematics. Am J Educ 2004, 110:256-281.

4. Wigfield A, Meece JL: Math anxiety in elementary and secondary school students. J Educ Psychol 1988, 80:210-216.

5. Newstead K: Aspects of children's mathematics anxiety. Educ Stud Math 1998, 36:53-71.

6. Yüksel-Şahin F: Mathematics anxiety among 4th and 5th grade Turkish elementary school students. Int Electronic J Math Educ 2008, 3:179-192.

7. Chiu L, Henry LL: Development and validation of the Mathematics Anxiety Scale for Children. Mes Eval Couns Devel 1990, 23:121-127.

8. Blatchford P: Pupils' views on school work and school from 7 to 16 years. Res Papers in Educ 1996, 11:263-288.

9. Dowker A: Individual differences in arithmetic: implications for psychology, neuroscience and education. Hove: Psychology Press; 2005.

10. Chinn S: Mathematics anxiety in secondary students in England. In Dyslexia: an International Journal of Research and Practice, Making Links: Selected Papers from the 7th Conference of the British Dyslexia Association, 68: 2009:61-68.

11. Khatoon T, Mahmood S: Mathematics anxiety among secondary school students in India and its relationship to achievement in mathematics. Eur J Soc Sci 2010, 16:75-86.

12. Betz NE: Prevalence, distribution, and correlates of math anxiety in college students. J Couns Psychol 1978, 25:441-448.

13. Ashcraft M, Faust M: Mathematics anxiety and mental arithmetic performance: an exploratory investigation. Cogn Emot 1994, 8:97-125.

14. Chipman SF, Krantz DH, Silver R: Mathematics anxiety and science careers among able college women. Psychol Sci 1992, 3:292-295.

15. Ho H-Z, Senturk D, Lam AG, Zimmer JM, Hong S, Okamoto Y, Chiu S-Y, Nakazawa Y, Wang C-P: The affective and cognitive dimensions of math anxiety: a cross-national study. J Res Math Educ 2000, 31:362-379.

16. Brown M, Brown P, Bibby T: "I would rather die": reasons given by 16year-olds for not continuing their study in mathematics. Res Math Educ 2010, 10:3-18

17. Richardson FC, Woolfolk RL: Mathematics Anxiety. In Test Anxiety: Theory, Research and Application. Edited by Sarason IG. Hillsdale, NJ: Erlbaum; 1980:275-288.

18. Dew KH, Galassi JP: Mathematics anxiety: some basic issues. J Couns Psychol 1983, 30:443-446.

19. Hembree R: The nature, effects, and relief of mathematics anxiety. J Res Math Educ 1990, 21:33-46.

20. Ashcraft MH, Kirk EP: The relationships among working memory, math anxiety, and performance. J Exp Psychol Gen 2001, 130:224-237.

21. Bai H: Cross-validating a bidimensional mathematics anxiety scale [abstract]. Assessment 2010, 18:115.

22. Hopko DR, Mahadevan R, Bare RL, Hunt MK: The abbreviated math anxiety scale (AMAS): construction, validity, and reliability. Assessment 2003, 10:178-182.

23. Ma X: A meta-analysis of the relationship between anxiety toward mathematics and achievement in mathematics. J Res Math Educ 1999, 30:520-540.

24. Miller $\mathrm{H}$, Bichsel J: Anxiety, working memory, gender, and math performance. Pers Individ Dif 2004, 37:591-606

25. Hopko DR, McNeil DW, Zvolensky MJ, Eifert GH: The relation between anxiety and skill in performance-based anxiety disorders: a behavioral formulation of social phobia. Behav Ther 2001, 32:185-207.

26. Kellogg JS, Hopko DR, Ashcraft MH: The effects of time pressure on arithmetic performance. J Anxiety Disord 1999, 13:592-600.
27. Tobias S: Anxiety and cognitive processing of instruction. In Self-related Cognitions in Anxiety and Motivation. Edited by Schwarzer R. Hillsdale, NJ: Lawrence Erlbaum Associates; 1986:35-54.

28. Wine J: Cognitive-attentional theory of test anxiety. In Test Anxiety: Theory, Research and Application. Edited by Sarason IG, Hillsdale NJ, Sarason IG. Hillsdale, NJ: Erlbaum; 1980:349-385.

29. Birgin O, Baloğlu M, Çatlıoğlu H, Gürbüz R: An investigation of mathematics anxiety among sixth through eighth grade students in Turkey. Learn Individ Differ 2010, 20:654-658.

30. Hackett G: Role of mathematics self-efficacy in the choice of mathrelated majors of college women and men: a path analysis. J Couns Psychol 1985, 32:47-56.

31. Hackett G, Betz NE: An exploration of the mathematics self-efficacy /mathematics performance correspondence. J Res Math Educ 1989, 20:261-273.

32. Meece $J$ L, Wigfield A, Eccles JS: Predictors of math anxiety and its influence on young adolescents' course enrollment intentions and performance in mathematics. J Educ Psychol 1990, 82:60-70.

33. Passolunghi MC: Cognitive and emotional factors in children with mathematical learning disabilities. Int J Disab Dev Educ 2011, 58:61-63.

34. Rubinsten $\mathrm{O}$, Tannock R: Mathematics anxiety in children with developmental dyscalculia. Behav Brain Fun 2010, 46:1-13.

35. Baloglu M, Kocak RA: Multivariate investigation of the differences in mathematics anxiety. Pers Individ Dif 2006, 40:1325-1335.

36. Baya'a NF: Mathematics anxiety, mathematics achievement, gender, and socio-economic status among Arab secondary students in Israel. Int $J$ Math Educ in Sci Tech 1990, 21:319-324.

37. Bernstein JD, Reilly LB, Coté-Bonanno JF: Barriers to women entering the workforce: math anxiety. New Jersey Equity Res Bull 1992, 3:3-6.

38. Dew KH, Galassi JP, Galassi MD: Math anxiety: relation with situational test anxiety, performance, physiological arousal, and math avoidance behavior. J Couns Psychol 1984, 31:580-583.

39. Eccles JS, Jacobs JE: Social forces shape math attitudes and performance. Signs 1985, 11:367-380

40. Else-Quest NM, Hyde JS, Linn MC: Cross-national patterns of gender differences in mathematics: a meta-analysis. Psychol Bull 2010, 136:103127.

41. Hopko DR: Confirmatory factor analysis of the math anxiety rating scalerevised. Educ Psychol Meas 2003, 63:336-351.

42. Hopko DR, McNiel DW, Lejuez C, Ashcraft MH, Eifert GH, Riel J: The effects of anxious responding on mental arithmetic and lexical decision task performance. J Anxiety Disord 2003, 17:647-665.

43. Jain S, Dowson M: Mathematics anxiety as a function of multidimensional self-regulation and self-efficacy. Contemp Educ Psychol 2009, 34:240-249.

44. Krinzinger H, Kaufmann L, Dowker A, Thomas G, Graf M, Nuerk HC, Willmes $\mathrm{K}$ : German version of the math anxiety questionnaire (FRA) for 6-to 9year-old children. Z Kinder Jugendpsychiatr Psychother 2007, 35:341-350.

45. Kyttala M, Bjorn PM: Prior mathematics achievement, cognitive appraisals and anxiety as predictors of Finnish students' later mathematics performance and career orientation. Educ Psychol 2010, 30:431-448.

46. Llabre MM, Suarez E: Predicting math anxiety and course performance in college women and men. J Couns Psychol 1985, 32:283-287.

47. Ma X, Cartwright FA: Longitudinal analysis of gender differences in affective outcomes in mathematics during middle and high school. Sch Eff Sch Improv 2003, 14:413-439.

48. Osborne JW: Testing stereotype threat: does anxiety explain race and sex differences in achievement? Contemp Educ Psychol 2001, 26:291-310.

49. Saigh PA, Khouri A: The concurrent validity of the mathematics anxiety rating scale for adolescents (MARS-A) in relation to the academic achievement of Lebanese students. Educ Psychol Meas 1983, 43:633-637.

50. Suinn RM, Taylor S, Edwards RW: Suinn mathematics anxiety rating scale for elementary school students (MARS-E): psychometric and normative data. Educ Psychol Meas 1988, 48:979-986.

51. Woodart T: The effects of math anxiety on post-secondary developmental students as related to achievement, gender, and age. Virginia Math Teacher 2004, Fall:7-9.

52. Cooper ST, Robinson DAG: The relationship of mathematics self-efficacy beliefs to mathematics anxiety and performance. Meas Eval Couns Dev 1991, 24:4-11.

53. Dede Y: Mathematics anxiety questionnaire: Development and validation. Essays in Education 2008, 23:1-22. 
54. Frary RB, Ling JL: A factor-analytic study of mathematics anxiety. EduC Psychol Meas 1983, 43:985-993.

55. Gierl MJ, Bisanz J: Anxieties and attitudes related to mathematics in grades 3 and 6. J Exp Educ 1995, 63:139-158.

56. Hadfield OD, Martin JV, Wooden S: Mathematics anxiety and learning style of the Navajo middle school student. Sch Sci Math 1992, 92:171-176.

57. Lupkowski AE, Schumacker RE: Mathematics anxiety among talented students. J Youth Adolesc 1991, 20:563-572.

58. Resnick H, Viehe J, Segal S: Is math anxiety a local phenomenon? A study of prevalence and dimensionality. J Couns Psychol 1982, 29:39-47.

59. Sepie A, Keeling B: The relationship between types of anxiety and underachievement in mathematics. J Educ Res 1978, 72:15-19.

60. Suinn RM, Taylor S, Edwards RW: The Suinn mathematics anxiety rating scale (MARS-E) for Hispanic elementary school students. Hispanic J Behav Sci 1989, 11:83-90.

61. Tapia M: The relationship of math anxiety and gender. Academic Exchange Quarterly 2004, 8:130-134

62. Abed AS, Alkhateeb HM: Mathematics anxiety among eighth-grade students of the United Arab Emirates [abstract]. Psychol Rep 2001, 89:65.

63. Reavis PS: Mathematics anxiety and the relationship between attitude, sex, ethnicity and achievement in mathematics in three high school curriculum tracks. PhD thesis: University of Arizona; 1989.

64. Sandman RS: Factors related to mathematics anxiety in the secondary school. San Francisco, California: Paper presented at the annual meeting of the American Educational Research Association; 1979.

65. Richardson FC, Suinn RM: The mathematics anxiety rating scale: psychometric data. J Couns Psychol 1972, 19:551-554.

66. Alexander L, Martray C: The development of an abbreviated version of the mathematics anxiety rating scale. Meas Eval Couns Dev 1989, 22:143-150.

67. Fennema E, Sherman JA: Fennema-Sherman mathematics attitudes scales: Instruments designed to measure attitudes toward the learning of mathematics by females and males. J Res Math Educ 1976, 7:324-326.

68. Plake BS, Parker CS: The development and validation of a revised version of the mathematics anxiety rating scale. Educ Psychol Meas 1982, 42:551-557.

69. Suinn RM, Winston EH: The mathematics anxiety rating scale, a brief version: psychometric data. Psychol Rep 2003, 92:167-173.

70. Sarason IG: The test anxiety scale: Concept and research. In Stress and Anxiety. Volume 5. Edited by Spielberger CD, Sarason IG. Washington DC: Hemisphere; 1978:193-216.

71. Szücs D: Teachers can substantially inform cognitive psychological and cognitive neuroscience research. J Profess Assoc Teach Specific Learn Disabil 2005, Nov:4-7.

72. Guiso L, Monte F, Sapienza P: Differences in test scores correlated with indicators of gender equality. Science 2008, 320:1164-1165.

73. Hyde JS, Fennema E, Lamon SJ: Gender differences in mathematics performance: a meta-analysis. Psychol Bull 1990, 107:139-155.

74. Spelke ES: Sex differences in intrinsic aptitude for mathematics and science? A critical review. Am Psychol 2005, 60:950-958.

75. Bander RS, Betz NE: The relationship of sex and sex role to trait and situationally specific anxiety types. J Res Pers 1981, 15:312-322.

76. Sherman J: Mathematics, spatial visualization, and related factors: changes in girls and boys, grades 8-11. J Educ Psychol 1980, 72:476-482.

77. Hunsley J, Flessati SL: Gender and mathematics anxiety: the role of mathrelated experiences and opinions. Anxiety Stress Coping 1988, 1:215-224.

78. Flessati SL, Jamieson J: Gender differences in mathematics anxiety: an artifact of response bias? Anxiety Stress Coping 1991, 3:303-312.

79. Biaggio MK, Nielsen EC: Anxiety correlates of sex-role identity. J Clin Psychol 1976, 32:619-623.

80. Meece JL, Parsons JE, Kaczala CM, Goff SB: Sex differences in math achievement: toward a model of academic choice. Psychol Bull 1982, 91:324-348.

81. Nolen-Hoeksema S: Sex differences in unipolar depression: evidence and theory. Psychol Bull 1987, 101:259-282.

82. Fennema E, Hart LE: Gender and the JRME. J Res Math EduC 1994, 25:648-659.

83. Fennema E, Sherman J: Sex-related differences in mathematics achievement, spatial visualization and affective factors. Am Educ Res $J$ 1977, 14:51-71.
84. Pintrich PR, de Groot EV: Motivational and self-regulated learning components of classroom academic performance. J Educ Psychol 1990, 82:33-40.

85. Sherman J, Fennema E: The study of mathematics by high school girls and boys: related variables. Am Educ Res J 1977, 14:159-168.

86. Wigfield A, Eccles JS, Maclver D, Reuman DA, Midgley C: Transitions during early adolescence: changes in children's domain-specific self-perceptions and general self-esteem across the transition to junior high school. Dev Psychol 1991, 27:552-565.

87. Pajares F: Gender differences in mathematics self-efficacy beliefs. In Gender differences in mathematics: An integrative psychological approach. Edited by Gallagher AM, Kaufmann JC. New York: Cambridge University Press; 2005:294-315

88. Brush LR: A validation study of the mathematics anxiety rating scale (MARS). Educ Psychol Meas 1978, 38:485-490.

89. Krinzinger $\mathrm{H}$, Kaufmann L, Willmes $\mathrm{K}$ : Math anxiety and math ability in early primary school years. J Psychoeduc Assess 2009, 27:206-225.

90. Evans J: Adults' mathematical thinking and emotions: A study of numerate practices. London: Falmer Press; 2000.

doi:10.1186/1744-9081-8-33

Cite this article as: Devine et al:: Gender differences in mathematics anxiety and the relation to mathematics performance while controlling for test anxiety. Behavioral and Brain Functions 2012 8:33.

\section{Submit your next manuscript to BioMed Central and take full advantage of:}

- Convenient online submission

- Thorough peer review

- No space constraints or color figure charges

- Immediate publication on acceptance

- Inclusion in PubMed, CAS, Scopus and Google Scholar

- Research which is freely available for redistribution 